\title{
An efficiency and security study of alage- water Separation by Electrocoagulation/flotation (ECF)
}

\author{
Xiaoxiao $\mathrm{Lu}^{1, \mathrm{a}}$, Liang $\operatorname{Tian}^{1, \mathrm{~b}}$, Tian $\mathrm{Xu}^{1, \mathrm{c}}$, Jinrui $\mathrm{Xu} \mathrm{u}^{1, \mathrm{~d}}$, Wei $\mathrm{Wu}^{1, \mathrm{e}^{*}}$ \\ ${ }^{1}$ Key Laboratory of Environmental Medicine and Engineering, Ministry of Education, School of \\ Public Health, Southeast University, Nanjing, 210009, China \\ a luxiao0720@126.com, ${ }^{\mathrm{b}}$ liangtiantaiyi@163.com, ${ }^{\mathrm{c}}$ 354158142@qq.com, ${ }^{\mathrm{d}}$ 1039995689@qq.com, \\ e *corresponding author101005800@seu.edu.cn
}

Keywords: algae separation, electrocoagulation/flotation, separation efficiency, cell integrity.

\begin{abstract}
The occurrence of algae in the water sources is a worldwide environmental health issue. Electrocoagulation/flotation (ECF), as an efficient, safety and environmental friendly algae removal technique without additional chemicals, shows obvious advantages on energy conservation and environmental security over conventional methods. In this study, the efficiency and security of algae separation in an ECF system were investigated. The algae removal, cell viability and extracellular MC-LR analysis were applied to access the effects of current density, run time and initial algal concentration on the separation efficiency and membrane integrity of cells. Results showed that within a reasonable range of parameters, ECF not only can achieve high efficiency of algae removal in a relatively short time but also ensure the integrity of algae cells. In this investigation, treat for 20 minutes at current density of $3 \mathrm{~mA} / \mathrm{cm}^{2}$ was found to be optimum under the experimental conditions.
\end{abstract}

\section{Introduction}

Algae bloom occurs in the source water, which is becoming a serious water quality problem for public and private water supplies. Massive development of algae in the source water may clog in the filter system and decrease the sensory properties of water such as turbidity, chromaticity and odor. Moreover, microcystins produced by algae can cause neurotoxicity, hepatotoxicity, nephrotoxicity and reproductive toxicity to animal and human ${ }^{[1,2,3]}$.

One possible solution to control the algal growth is to harvest algae from the medium (reservoirs, lakes and rivers), especially control the water quality of the water intake. Numerous techniques, such as membrane treatment, ultrasonic treatment, sedimentation and air flotation, are popular in wastewater treatment. However, traditional methods for removing algae not only energy- or time-consuming but also have the risk of secondary pollution ${ }^{[4,5,6]}$.

Electrocoagulation/flotation (ECF), as an efficient, safety and environmental friendly algae removal technique without additional chemicals, shows obvious advantages on energy conservation and environmental security over conventional methods. However, nowadays the researches mainly focus on the algae efficiency, little information about the security verification in the algae water separation process could be found. Electro-oxidation/disinfection, one of the mechanisms takes place in the ECF system, may cause microalgae lysis then lead to the release of toxins into surrounding water, which will present a more serious hazard to water safety due to the more difficult removal of dissolved toxins than the whole cells ${ }^{[7]}$.

In this study, the efficiency and security of the algae water separation in electrocoagulation/flotation (ECF) process will be discussed. In order to evaluate it, the algae removal efficiency were put as the first choice. Moreover, the effect of pre-set conditions on the integrity of the cells was measured by the changes of extracellular MCs and cell viability. Finally, according to the experiment data, the optimal parameters which under the premise of ensuring the integrity of the cell can achieve a higher removal rate, were selected to guide the actual operation. All of these experiments were aiming at establishing a fast, efficient and environmental friendly algaecide system in response to algae bloom outbreaks in the drinking water supply system. 


\section{Materials and methods}

\section{Preparation of the algal suspension}

The target algae, Microcystis aeruginosa (FACHB-905), was provided from the Fresh Algae Culture Collection of the Institute of Hydrobiology, Chinese Academy of Sciences ${ }^{[8]}$. Biomass was cultured by the methods of Qiu et al ${ }^{[9]}$. The initial algal concentration was $1.5 \times 10^{9} / \mathrm{L}$ to investigate the effect of initial cell density and culture solution was diluted by deionized water.

\section{The ECF experimental device}

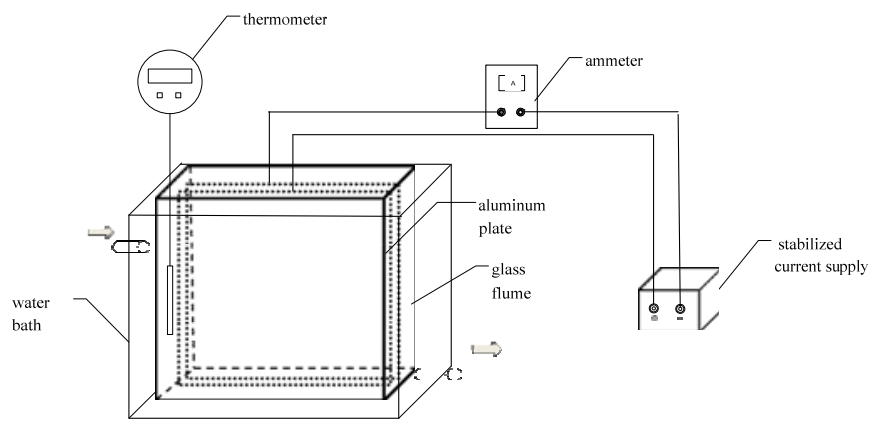

Fig.1 Schematic diagram of the experimental device

ECF experiments were carried out in a glass flume with configuration of $25.5 \mathrm{~cm}$ (length) $X$ $10 \mathrm{~cm}$ (width) $\times 30 \mathrm{~cm}$ (height) is schematically shown in Fig.1. All the experiments were carried out at room temperature by using $6 \mathrm{~L}$ of algal suspension culture. Two aluminum plates $(25 \mathrm{~cm} \times 0.3 \mathrm{~cm}$ $\times 25 \mathrm{~cm}$ ), used as the electrode material with the effective area of $625 \mathrm{~cm}^{2}$, were kept $3 \mathrm{~cm}$ apart fixed to the flume casing. The applied current was regulated from the DC power supply (WYJ-0-30V/3A, China). The initial $\mathrm{pH}$ of the samples was adjusted to $7.0 \pm 0.2$.

\section{The efficiency of the algae separation}

The algal concentration was calculated based upon the decrease in optical density of the algal culture (measured at $628 \mathrm{~nm}$ with a UV-vis spectrometer,752, China). Samples were collected $5 \mathrm{~cm}$ below the water surface in the reactor which was allowed to settle for $20 \mathrm{~min}$. And the removal efficiency could be calculated using the following formula: $Y=\frac{C_{0}-C_{t}}{C_{0}}$, where $Y$ is the removal efficiency, $C_{0}$ is the initial concentration, $C_{t}$ is the final concentration at any time.

\section{The integrity of the cells}

Cell activity, which was determined using a microscope assay with fluorescein diacetate (FDA) and propidium iodide (PI), is an index used to assess the integrity of the algae. In this method, cells were examined with a BX51 microscope (OLYMPUS) after being stained with FDA and PI. Cells with an intact cell membrane are stained bright green by FDA and cells with a damaged cell membrane are stained bright red with PI.

Extracellular MC-LR was monitored using an Agilent 1100 HPLC machine with a Zorbax Extend C18 column ( $4.66150 \mathrm{~mm}, 5 \mathrm{um}$, Agilent, USA) and a variable wavelength detector (VWD) set at $238 \mathrm{~nm}$. The mobile phase was a mixture of methanol and $0.1 \%$ trifluoroacetic acid aqueous solution $(55: 45, \mathrm{v} / \mathrm{v})$ set at a flow rate of $1 \mathrm{~mL} / \mathrm{min}$. The column temperature was maintained at $40^{\circ} \mathrm{C}$ and the injection volume was $20 \mathrm{uL}$. 


\section{Results and Discussion}

\section{The efficiency of the algae separation}

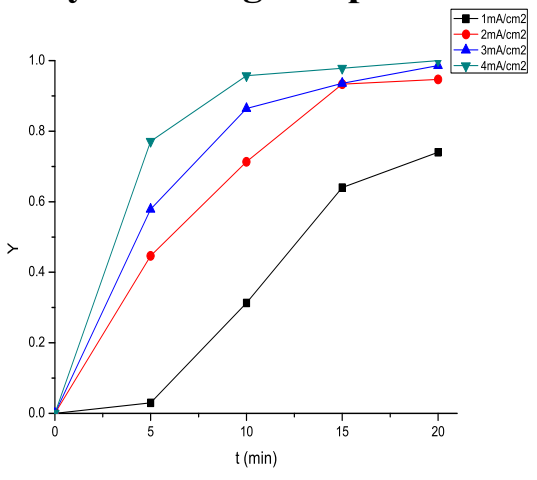

(a)

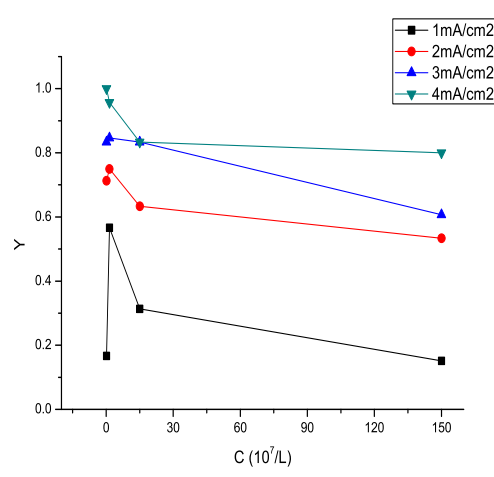

(b)

Fig.2 The changes of algae removal efficiency

(Fig.a shows the effects of current density on algae removal efficiency. Fig.b shows the effects of initial concentration on algae removal efficiency. )

From Fig. 2(a), we can easily know that the removal rate of algae increased with the current density and the run time. Generally speaking, in order to reach the goal of a rapid algae removal, there needs a collision and adhesion between the flocs, algae and bubbles ${ }^{[10]}$. Additionally, it is well known that the run time and electric current density not only determine the metal coagulant dissolution rate but also determine the bubble production rate and the size of the bubble generated in the electrode reaction, which influence the treatment efficiency of the ECF process ${ }^{[11]}$. As the current density and run time increase, the aluminum ions which dissolve from the anode would increase in water. Thus, there will be an increasing number of aluminum hydroxide flocs for the removal of algae. Moreover, the algae removal rate under different current densities showed the same trends with run time increased: At the beginning of the reactive stage there is a rapid rise in the removal efficiency, with the process of reaction, the system moves into the stable stage. According to Faraday's law, in the case of constant current, the amount of flocs and bubbles released is certain in a certain period of time. In the early stage of the reaction, the high concentration of algae makes the collision more effective. With the process of reaction, the concentration of algae decreased, hence there is a reduction in the probability of collision and adhesion between the flocs, algae and bubbles. Fig.2a also present that under the same run time, the higher the current density, the better the effect of algae removal. The algae removal increased followed to the current density rose from $1 \mathrm{~mA} / \mathrm{cm}^{2}$ to $4 \mathrm{~mA} / \mathrm{cm}^{2}$. When the run time was kept at $20 \mathrm{~min}$, the algae removal efficiency of $1 \mathrm{~mA} / \mathrm{cm}^{2}, 2 \mathrm{~mA} / \mathrm{cm}^{2}, 3 \mathrm{~mA} / \mathrm{cm}^{2}, 4 \mathrm{~mA} / \mathrm{cm}^{2}$ were $74 \%$, $94.67 \%, 98.57 \%, 100 \%$ respectively. Moreover, at higher current density, less ECF time would be required to remove algae from water.

As in shown in Fig. 2(b), when the current density is from $1 \mathrm{~mA} / \mathrm{cm}^{2}$ to $3 \mathrm{~mA} / \mathrm{cm}^{2}$, the algae removal efficiency firstly increased and reached the highest value at $1.5 \times 10^{7} / \mathrm{L}$ then decreased as the algal concentration rose from $1.5 \times 10^{6} / \mathrm{L}$ to $1.5 \times 10^{9} / \mathrm{L}$. when the current density is $4 \mathrm{~mA} / \mathrm{cm}^{2}$, with the increase of the initial concentration of algae, the algae removal efficiency was decreased. Therefore. We suggest a hypothesis that the initial concentration of $1.5 \times 10^{7} / \mathrm{L}$ could be a critical concentration point. The effects of initial concentration on algae removal was different from Gao et al ${ }^{[12]}$ may be caused by the efficiency of the collision changed, because the effective remove requires adequate contact between the coagulant, algae cells and bubbles ${ }^{[11]}$. When the initial concentration is $1.5 \times 10^{6} / \mathrm{L}$, due to the low concentration of algae, the collision is relatively difficult, so the algae removal efficiency is low. As the current density increased, the aluminum ions which dissolve from the anode would increase in water which provide a possibility to have a high efficiency of collision. However, when the initial concentration is $1.5 \times 10^{7} / \mathrm{L}$, under the same flocs and bubble conditions, the collision rate is still increasing and close to or maybe have reached the saturation. Therefore, although the algae concentration increased from $1.5 \times 10^{8} / \mathrm{L}$ to $1.5 \times 10^{9} / \mathrm{L}$, 
the algae removal efficiency is still decrease.

\section{The integrity of the cells}

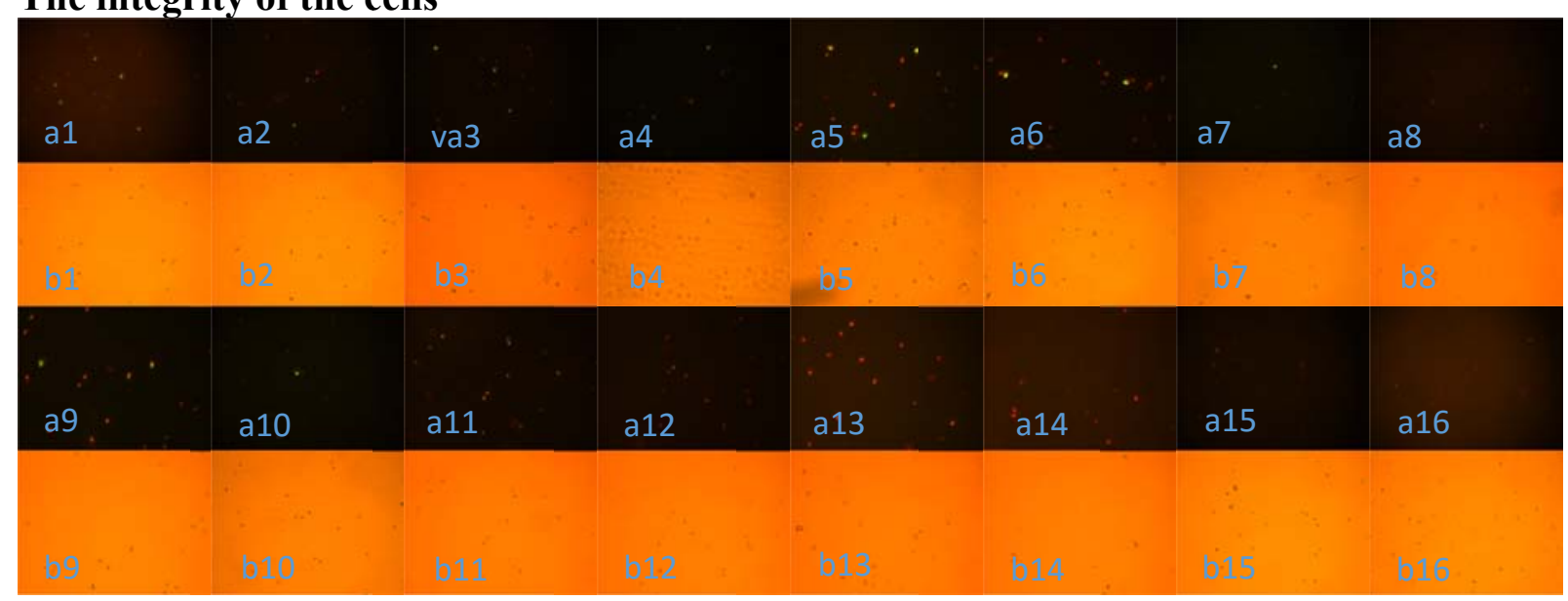

Fig.3 The cell viability microscope images

(When current density is $1 \mathrm{~mA} / \mathrm{cm}^{2}$, the cell viability at $5 \mathrm{~min}, 10 \mathrm{~min}, 15 \mathrm{~min}, 20 \mathrm{~min}$ are a1, a2, a3, a4 respectively. In the same way, the cell viability of a5-a8, a9-a12, a13-a16 are $2 \mathrm{~mA} / \mathrm{cm}^{2}$, $3 \mathrm{~mA} / \mathrm{cm}^{2}, 4 \mathrm{~mA} / \mathrm{cm}^{2}$ respectively. The b1-b16 are corresponding bright field diagram with a1-a16.)
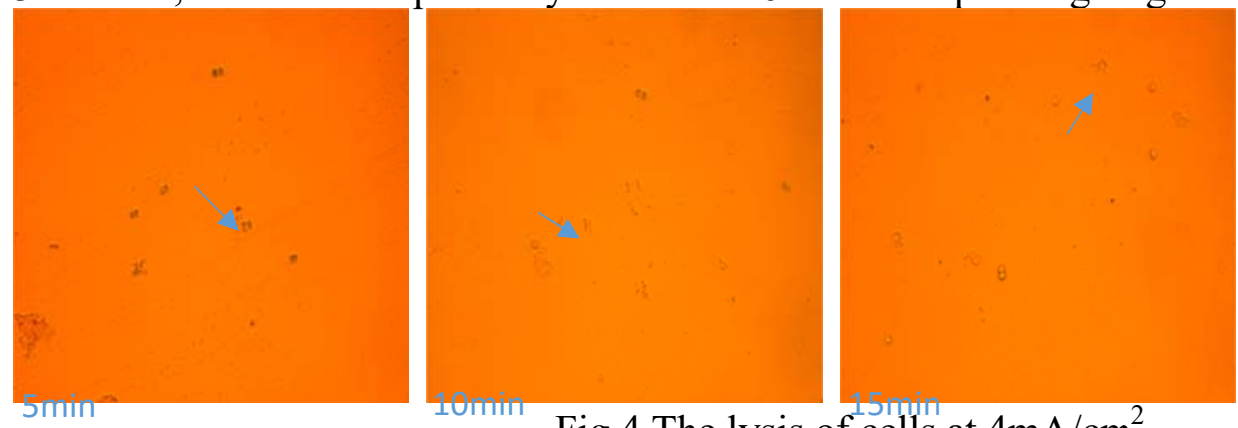

Fig.4 The lysis of cells at $4 \mathrm{~mA} / \mathrm{cm}^{2}$

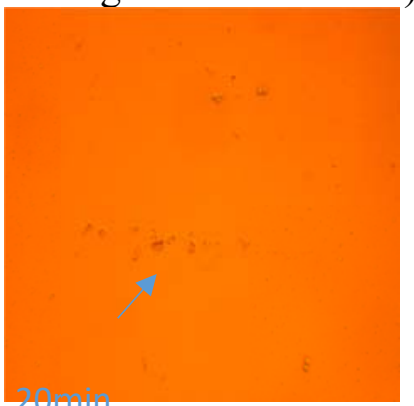

During the ECF process, the electro-oxidation/disinfection has been confirmed to achieve the effect of sterilization by change the pressures on cell membrane ${ }^{[13]}$. In order to assess the effect of electro-oxidation/disinfection on the cell integrity of cultured algae, the extracellular MC-LR and cell viability were measured, to carry out an effective analysis. In this experiment ,we set the initial algal concentration is $1.5 \times 10^{9} / \mathrm{L}$. The effect of current density at $1 \mathrm{~mA} / \mathrm{cm}^{2}, 2 \mathrm{~mA} / \mathrm{cm}^{2}, 3 \mathrm{~mA} / \mathrm{cm}^{2}$, $4 \mathrm{~mA} / \mathrm{cm}^{2}$ on the integrity of the cells was measured by damage of cells and increase of extracellular MC-LR. Run times of the current density were determined at 5, 10, 15, $20 \mathrm{~min}$.

It can be seen from Fig.5 that viable and inactive cells were stained as bright green and red fluorescent cells, respectively, by FDA and PI under blue excitation. And in the inactive/viable cell systems, the proportion of inactive cells in the solutions increased with the increase of current density. Moreover, Fig.4 shows the algae inactivation as a function of run time. The similar results were also obtained by Furuta team ${ }^{[14]}$. The greater the current density, the longer the run time, the more serious of cell damage is. When the current density was $1 \mathrm{~mA} / \mathrm{cm}^{2}$ and the run time was $5 \mathrm{~min}$, some algae cells were stained red, however, observed in the bright field the morphological of cell is integrity. While the current density went up to $4 \mathrm{~mA} / \mathrm{cm}^{2}$, all of the algae cells were stained red and the cell began to burst, with the increase of the run time, cell lysis became more and more serious

Fig. 6 shows the cell debris caused by short-lived and high-energy intermediate ECF products ${ }^{[13]}$. This result indicated that algae cells were separated with damage to membrane integrity. Cell damage is mainly caused by the strong oxidizing substances produced in the ECF process ${ }^{[13]}$. Even though these substances have a short exit time and a low content, they are sufficient to cause cell damage ${ }^{[11]}$. The strong oxidizing substances is increasing followed by the run time and current density, therefore, the damage of the cells is more and more serious. 


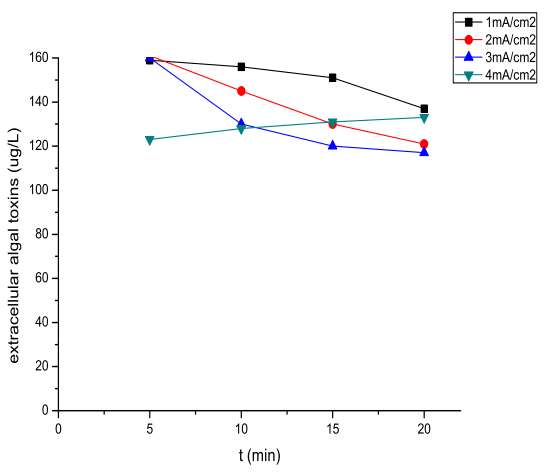

Fig.5 The changes of extracellular MC-LR

The MC-LR, which were generally considered to be caused by the rupture of algal cells in the water $^{[15]}$, can cause animal and human tumor promotion. Therefore, the changes of MC in the sample water should be determined after the algae treated with ECF. The changes of extracellular MC-LR in the solutions with pre-set conditions were plotted in Fig.7. It can be seen that at the current density except $4 \mathrm{~mA} / \mathrm{cm}^{2}$, the extracellular MC-LR concentration exhibited a slow decrease as the extension of time. Moreover, at higher current density, faster rate would be acquired to degrade extracellular MC-LR from water. As the current density is $3 \mathrm{~mA} / \mathrm{cm}^{2}$, the extracellular MC-LR concentration decreased from $159 \mathrm{ug} / \mathrm{L}$ to $131 \mathrm{ug} / \mathrm{L}$ within $20 \mathrm{~min}$. By contrast, the extracellular MC-LR concentration underwent a more gradual increase at $4 \mathrm{~mA} / \mathrm{cm}^{2}$, and an $8.1 \%$ increase in toxin level was detected with $20 \mathrm{~min}$. The degradation of MC-LR could be ascribed to the oxidation of hydroxyl radicals produced in the ECF process. Nevertheless, when the current density rose to $4 \mathrm{~mA} / \mathrm{cm}^{2}$, the cell break down and release the MC-LR into the surrounding water $[16,17]$.

\section{Conclusion}

In this study, the efficiency and security of algae separation in an ECF system were investigated. The following conclusions could be drawn according to the experimental results.

(1) ECF achieve high efficiency of algae removal in a relatively short time, it can be well applied to achieve the separation of the algae and water efficiently.

(2)The effect of electro-oxidation/disinfection under pre-set conditions could cause obvious damage to the cells. And the damaged cells, which could release the intracellular MC-LR into the surrounding water, would increase the processing difficulty.

(3)The current density should be optimized when considering the algae removal cell viability and extracellular MC-LR simultaneously. In this investigation, treat for 20 minutes at current density of $3 \mathrm{~mA} / \mathrm{cm}^{2}$, which ensured the efficiency and security, was found to be optimum under the experimental conditions.

\section{Reference}

[1] I. R. Falconer, A. R. Humpage, Health risk assessment of cyanobacterial (blue-green algal) toxins in drinking water, Int J Environ Res Public Health. 2(2005) 43-50.

[2] L. Bláha, P. Babica, B. Maršálek, Toxins produced in cyanobacterial water blooms - toxicity and risks, Interdisciplinary Toxicology. 2 (2009) 36-41.

[3] H. Zhang, C. Cai, Y. Wu, B. Ye, L. Han, X. Shou, M. Wang, J. Wang, X. Jia, Toxic effects of microcystin-LR on the reproductive system of male Rana nigromaculata in vitro, Aquat Toxicol. 126 (2013) 283-290.

[4] M. Cerff, M. Morweiser, R. Dillschneider, A. Michel, K. Menzel, C. Posten, Harvesting fresh water and marine algae by magnetic separation: Screening of separation parameters and high gradient magnetic filtration, Bioresource Technol. 118 (2012) 289-295. 
[5] X. Wu, E.M. JoyceT. J. Mason, Evaluation of the mechanisms of the effect of ultrasound on Microcystis aeruginosa at different ultrasonic frequencies, Water Res. 46 (2012) 2851-2858.

[6] H. Xiong, Y. Li, Q. Zhang, Mechanical removal and dewatering of cyanobacteria blooms in Chaohu Lake, Chinese Journal of Enviromental Engineering. 8(2014)599-604.

[7] F. Sun, H. Pei, W. Hu, X. Li, C. Ma, R. Pei, The cell damage of Microcystis aeruginosa in PACl coagulation and floc storage processes, Sep Purif Technol. 115 (2013) 123-128.

[8] S. Gao, M. Du, J. Tian, J. Yang, J. Yang, F. Ma, J. Nan, Effects of chloride ions on electro-coagulation-flotation process with aluminum electrodes for algae removal, J. Hazard Mater. 182 (2010) 827-834.

[9] Y. J. Qiu, F Rong, F.Yang, J. P. Li, H. Long, W. Wu, Ultrasound Frequency Impacts On the Removal of Indigenous Blue-green Algae Taken From Lake Taihu, In Advanced Materials Research, Fan W, 'Ed.'; TRANS TECH PUBLICATIONS LTD: STAFA-ZURICH. (2012) 3758-3762.

[10] P.K. Holt, G.W. Barton, M. Wark, C.A. Mitchell, A quantitative comparison between chemical dosing and electrocoagulation, Colloids and Surfaces A: Physicochemical and Engineering Aspects. 211(2002) 233-248.

[11] J. Li, C. Song, Y. Su, H. Long, T. Huang, T.O. Yeabah, W. Wu, A study on influential factors of high-phosphorus wastewater treated by electrocoagulation-ultrasound, Environ Sci Pollut Res Int. 20 (2013) 5397-5404.

[12] S. Gao, J. Yang, J. Tian, F. Ma, G. Tu, M. Du, Electro-coagulation-flotation process for algae removal, J. Hazard Mater. 177 (2010) 336-343.

[13] X.Y. Li, H.F. Diao, F. Fan, J.D. Gu, F. Ding, A. Tong, Electrochemical wastewater disinfection: Identification of its principal germicidal actions, JOURNAL OF ENVIRONMENTAL ENGINEERING-ASCE. 130 (2004) 1217-1221.

[14] T. Furuta, H. Tanaka, Y. Nishiki, L. Pupunat, W. Haenni, P. Rychen, Legionella inactivation with diamond electrodes, Diam Relat Mater. 13 (2004) 2016-2019.

[15] W.W. Carmichael. A Status Report on Planktonic Cyanobacteria(Blue Green Algae) and Their Toxins. US Environmental Protection Agency/600/R-92/079, Washington, DC, 1992, pp. 15-26.

[16] C. Ross, L. Santiago-Vázquez, V. Paul, Toxin release in response to oxidative stress and programmed cell death in the cyanobacterium Microcystis aeruginosa, Aquat Toxicol. 78 (2006) 66-73.

[17] L.N. Sangolkar, S.S. Maske, T. Chakrabarti, Methods for determining microcystins (peptide hepatotoxins) and microcystin-producing cyanobacteria, Water Res. 40 (2006) 3485-3496. 